\title{
New Tool Explains Live Mycobacteria Found in Retail Milk
}

\author{
Berwyn Clarke* \\ Chief Executive, PBD Biotech, $U K$ \\ *Corresponding author: Berwyn Clarke, Chief Executive, PBD Biotech, UK
}

\section{Short Communication}

Most consumers of dairy products accept that pasteurization provides a guarantee that products are safe to eat and drink. However, research [1] using a new highly sensitive technology has revealed that live mycobacteria can exist in retail milk even after pasteurization and explains how this may happen. Live Mycobacterium avium subspecies paratuberculosis (MAP) - which causes Johne's disease in cattle and has been implicated in Crohn's disease in humans - was found in just over $10 \%$ of shop-bought pasteurized milk samples that were tested in the UK. The prevalence of MAP is higher than previous studies have shown due to the high sensitivity of the new phage-based technology that was used to conduct the milk testing. In the study of 386 samples of retailpurchased milk, Actiphage was able to detect live mycobacteria at levels as low as 1-2 cells per $50 \mathrm{ml}$ in comparison to other tests that cannot detect cell-counts lower than 100 cells. There is a growing body of research that implicates MAP in the development of Crohn's disease [2], with MAP found in the bowel tissue of a proportion of patients with the condition. Although no causal relationship between MAP and Crohn's has been directly established the dairy industry recognizes that limiting human exposure to MAP would be sensible on a precautionary principle [3]. Furthermore, there are clinical trials underway with anti-mycobacterial drugs that are directly assessing the benefit in Crohn's disease. Some retailers are already removing dairy farmers from their milk pool if they are not engaged with Johne's control plans.

The Actiphage assay, developed by PBD Biotech, uses a virus (phage) that finds, infects and replicates in viable mycobacteria cells. Within hours the virus breaks open the mycobacteria cells, releasing DNA determining whether live organisms were present in the sample. Previous quality control procedures to monitor the levels of MAP in pasteurized milk have been difficult as these mycobacteria are extremely slow growing. Culturing these bacteria takes up to 18 weeks to determine if any MAP cells have survived a food safety or control process and the sensitivity of the procedure is low. The new phage-based detection method, which was used within the research published in the Elsevier journal of Food Microbiology (September 2018) [1], allowed experiments to be performed quickly (6-8 hours); providing the insight dairy producers and processors need to further improve control measures. The test's underlying biotechnology was originally used for the detection of human TB-under the FastPlaque brand - but was only suitable for use on sputum. Now the highly specific phagebased diagnostic has been optimized, so it can detect the presence of mycobacteria in blood or milk in just six hours. Contrary to previous hypotheses, this research also suggests that MAP does not enter the milk solely due to faecal contamination, but via somatic cells within the udder. This intracellular location and the fact that these cells appear to clump may help explain how the mycobacteria are protected against heat inactivation during pasteurization and could lead to new processing methods to ensure the mycobacteria are inactivated. Earlier published work in 2016 [4] using the same technology also demonstrated the presence of live MAP in infant formula milk further increasing the value of this technology as a screening tool.

Additionally, for the farmgate milk industry and dairy producers using raw milk, the ability of Actiphage to detect extremely low levels of mycobacteria means it is a vital tool for food safety and quality assurance. In the UK, where bovine tuberculosis (bTB) is endemic in swathes of the national herd alongside Johne's disease, the existing standard skin-test has a variable sensitivity potentially missing up to $50 \%$ of infected cattle, with the risk that bulk tank milk may be contaminated with live mycobacteria. For example, a retrospective bTB outbreak in a source herd of the raw milk used in unpasteurized cheese manufacture could mean a year's worth of produce being thrown away, potentially bottoming a 
business beyond recovery. South of England cheesemaker James Montgomery has been using Actiphage as an insurance policy for his dairy produce for several years. James makes cheddar and raw-milk cheese from his 180 Jersey cows and 200 Holstein Friesians [5,6]. Before Actiphage there was no way of testing bulk tank milk directly for the presence of bTB. In May 2018, Actiphage was accepted by the UK Government's Animal and Plant Health Agency for exceptional private use on herds stricken with bTB in England. Much of this new strategy was driven by the success of veterinarian Dick Sibley, who incorporated Actiphage into a disease management strategy, to help clear a dairy herd that had been stricken with TB since 2012. With growing international interest in the Actiphage milk and blood tests, further trials are underway in the UK, US and Canada. Research shows that the phage-based assay provides a powerful new tool to help farmers, producers and processors rapidly test milk, milk formula and other dairy products as part of bulk milk testing and quality assurance programmesenabling the livestock and dairy sector to stay one step ahead of consumer demand.

\section{References}

1. Gerrard, Benjamin MC Swift, George Botsaris, Ross S Davidson, Michael R Hutchings, et al. (2018) Survival of Mycobacterium avium subspecies paratuberculosis in retail pasteurised milk. Food Microbiology 74: 5763.

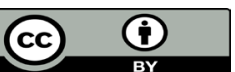

This work is licensed under Creative Commons Attribution 4.0 License

Submission Link: Submit Article

DOI: $10.32474 /$ CDVS.2019.02.000141
2. Bull, McMinn EJ, Sidi-Boumedine K, Skull A, Durkin D, Neild P, et al. (2003) Detection and verification of Mycobacterium avium subsp paratuberculosis in fresh ileocolonic mucosal biopsy specimens from individuals with and without Crohn's disease. Journal of Clinical Microbiology 41(7): 2915-2923.

3. Feller, Huwiler K, Stephan R, Altpeter E, Shang A, et al. (2007) Mycobacterium avium subspecies paratuberculosis and Crohn's disease: a systematic review and meta-analysis. Lancet Infectious Diseases 7(9): 607-613.

4. Rhodes, Richardson H, Hermon-Taylor J, Weightman A, Higham A, et al. (2014) Mycobacterium avium Subspecies paratuberculosis: Human Exposure through Environmental and Domestic Aerosols. Pathogens 3(3): 557-595.

5. National Advisory Committee on microbiological criteria for foods (2010) Assessment of Food as a Source of Exposure to Mycobacterium avium subspecies paratuberculosis (MAP). Journal of Food Protection 73(7): 1357-1397.

6. Botsaris, Swift BM, Slana I, Liapi M, Christodoulou M, et al. (2016) Detection of viable Mycobacterium avium subspecies paratuberculosis in powdered infant formula by phage-PCR and confirmed by culture. International Journey of Food Microbiology 216: 91-94. 